\title{
MACHINE LEARNING RISK FACTORS ON THE ROMANIAN STOCK MARKET
}

\author{
Dan Gabriel ANGHEL \\ Department of Money and Banking \\ Bucharest University of Economic Studies, Romania \\ dan.anghel@fin.ase.ro
}

\begin{abstract}
We analyze risk factors on the stock market of Romania using Machine Learning classification models and find novel evidence showing that Volatility, Conditional Skewness and Liquidity display significant predictive power over long-term stock returns. In our sample, a portfolio formed using information derived from these, plus the classical Market, Size, Value and Momentum factor, earns an average excess return of roughly $12 \%$ per year, which is significant with $t \geq 3$.
\end{abstract}

Keywords: Asset Pricing, Risk Factors, Stock Market, Machine Learning, Artificial Intelligence

JEL classification: G11, G12

DOI: $10.24818 / \mathrm{ie} 2020.04 .07$

\section{Introduction}

Many risk factors have been investigated as possible asset price determinants in international financial markets ([9]). However, only a handful of those have been tested in small, less developed markets.

This paper contributes to the literature by analyzing some of the previously uninvestigated risk factors in the frontier stock market of Romania, using an unconventional approach that relies on prediction models derived from Machine Learning (ML) algorithms. In essence, we use trading histories and past balance sheet information to fit a ML model that is used to forecast future stock prices and construct a portfolio capable of generating significant alphas relative to well-known, benchmark asset pricing models.

This is not the first paper that uses ML algorithms to investigate asset pricing factors in the stock market. Similar applications exist in developed (e.g., [8]) or emerging markets (e.g., [11]). Nor is it the first that uses such algorithms to forecast stock market prices in Romania. Previous examples, including [2] or [12], focus on their raw prediction performance over stock prices, mainly market indices.

However, it is the first that combines the two in a way that is relevant for "learning" candidate asset pricing factors that have informational content and influence long-term stock returns. The actual input variables are selected from classes that can be associated with candidate risk factors, such as Market, Size, Value, Momentum, or Volatility (these have been investigated before). However, we also incorporate factors that have not been tested for Romania and, more generally, for any emerging market in the Eastern European region. Specifically, we use the Conditional Skewness factor of [10], or the Liquidity factor of [5].

These are supplemented by other variables that describe aggregate macroeconomic conditions or the cross-sectional dispersion of stock returns. We consecutively test all the factors relative to three benchmark models, namely the Capital Asset Princing Model ([13]), the Fama-French 3-factor model ([6]) and the Carhart 4-factor model ([4]). 
www.conferenceie.ase.ro

\section{Data and methodology}

\subsection{Data}

The data sample consists of all stocks traded on the Romanian stock market, The Bucharest Stock Exchange, in the period March 2005 to January 2020. Daily trading data, consisting of prices, number of trades, volume and share turnover (volume times average price, expressed in local currency) are collected from the brokerage firm Tradeville (2005-2015) and from Bloomberg (2015-2020). A total of 555,424 unique observations are used. The market portfolio is proxied by the BET index. Individual stocks that are traded in less than half of all possible days are filtered out due to very low liquidity, leaving a sample of 68 firms. For these, we use market prices to compute log-returns on each trading day. The resulting daily trading data is used to compute variables associated with asset pricing factors at the monthly frequency. The risk free interest rate is proxied by the yield on 1-year bonds issued by the Romanian government.

Table 1. List of variables used in the analysis

\begin{tabular}{|c|c|c|}
\hline Type & Variable & Description \\
\hline \multirow[t]{3}{*}{ Market } & Beta $1 \mathrm{~m}$ & $\begin{array}{l}\text { Firm-level systematic risk measure, estimated with the regression } R_{i, t}=\alpha_{i}+ \\
\beta_{i} R_{m, t}+\varepsilon_{m, t} \text {, using daily observations on stock returns in the previous } 1 \text { month. }\end{array}$ \\
\hline & Beta $6 m$ & Idem, except that data in the previous 6 months is used. \\
\hline & Beta $1 \mathrm{y}$ & Idem, except that data in the previous 1 year is used. \\
\hline Size & MkCap & $\begin{array}{l}\text { Firm-level market capitalization, computed as the current price times the total } \\
\text { number of ordinary shares outstanding. }\end{array}$ \\
\hline Value & $\begin{array}{l}\text { Book-to- } \\
\text { Market }\end{array}$ & $\begin{array}{l}\text { Firm-level Book-to-Market ratio, computed as total equity divided by market } \\
\text { capitalization }\end{array}$ \\
\hline \multirow[t]{6}{*}{ Momentum } & Mom 1w & Firm-level cumulative return of stock prices in the previous 1 week. \\
\hline & Mom 2w & Idem, except that data in the previous 2 weeks is used. \\
\hline & Mom 3w & Idem, except that data in the previous 3 weeks is used. \\
\hline & Mom $1 \mathrm{~m}$ & Idem, except that data in the previous 1 month is used. \\
\hline & Mom 6m & Idem, except that data in the previous 6 months is used. \\
\hline & Mom 1y & Idem, except that data in the previous 1 year is used. \\
\hline \multirow[t]{6}{*}{ Volatility } & Vol 1w & Firm-level standard deviation of stock returns in the previous 1 week. \\
\hline & Vol 2w & Idem, except that data in the previous 2 weeks is used. \\
\hline & Vol 3w & Idem, except that data in the previous 3 weeks is used. \\
\hline & Vol 1m & Idem, except that data in the previous 1 month is used. \\
\hline & Vol 6m & Idem, except that data in the previous 6 months is used. \\
\hline & Vol 1y & Idem, except that data in the previous 1 year is used. \\
\hline \multirow[t]{2}{*}{$\begin{array}{l}\text { Conditional } \\
\text { Skewness }\end{array}$} & Skew $6 \mathrm{~m}$ & $\begin{array}{l}\text { Firm-level conditional skewness ([10]) computed over a } 6 \text {-month lookback } \\
\text { interval. }\end{array}$ \\
\hline & Skew 1y & Idem, except that data in the previous 1 year is used. \\
\hline \multirow[t]{6}{*}{ Liquidity } & Turn $1 \mathrm{w}$ & Firm-level cumulative market turnover in the previous 1 week. \\
\hline & Turn $2 \mathrm{w}$ & Idem, except that data in the previous 2 weeks is used. \\
\hline & Turn $3 \mathrm{w}$ & Idem, except that data in the previous 3 weeks is used. \\
\hline & Turn $1 \mathrm{~m}$ & Idem, except that data in the previous 1 month is used. \\
\hline & Turn $6 \mathrm{~m}$ & Idem, except that data in the previous 6 months is used. \\
\hline & Turn $1 \mathrm{y}$ & Idem, except that data in the previous 1 year is used. \\
\hline \multirow[t]{5}{*}{ Macro } & EXRATE & Appreciation or depreciation (YoY) of the EUR/RON exchange rate. \\
\hline & GDP & Real GDP growth rate (YoY). \\
\hline & INFL & Growth rate of consumer prices in the economy (YoY). \\
\hline & UNMPL & Unemployment level. \\
\hline & CAD & Current Account Deficit, expressed as a percent of GDP. \\
\hline
\end{tabular}


WWw.conferenceie.ase.ro

DEBT Total country debt, expressed as a percent of GDP.

Other CSSD 1-month average of the series of Cross Sectional Standard Deviations of returns, computed for all stocks in the filtered sample.

\subsection{Risk factors}

This paper tests for possible surplus informational content in some well-chosen variables that proxy established and candidate asset pricing factors. The variables that we incorporate in the analysis are listed and explained in Table 1.

\subsection{Machine learning forecasting model}

We use the Random Forest ML technique ([3]) in order to train a model that uses the selected features to make predictions about future price movements. First, we define a classification variable that the model fits and predicts. Because we are interested in using the features to make forecasts about future stock returns, we use the 1-month-ahead excess return of each stock compared to the market return. Because we use a classification algorithm, we convert this into a binary variable that takes 1 when the excess return is positive and 0 otherwise. The target variable is added for each stock and for each month alongside the rest of the data sample. Second, we choose an initial training sample of 3 / 8 of the entire sample, which makes May 2011 the initial cutoff date in our case. All observations before this date are added to the training sample, while the observations exactly on this date constitute the test (prediction) sample. The target variable is eliminated from the prediction samples, to avoid look-ahead bias. Third, we fit a 5000-tree Random Forest model on the training sample and use it to make a 1-monthahead out-of-sample prediction about future returns using the features computed for each stock at the beginning of the current cutoff month. The predictions are then used to form a portfolio at the beginning of the month, which is held until the next prediction is made. This procedure is repeated recursively for all other months in the sample following May 2011, with the model being re-trained at every step.

Returns on the market portfolio (proxied by the BET index) and hedge portfolios, SMB, HML and MOM, are also computed, the latter three using the rebalancing procedure of [7], which was also used by [1]. The resulting series enable the evaluation of ML portfolio returns relative to established asset pricing models, namely the CAPM ([13]), the Fama-French 3-factor model ([6]) and the Carhart 4-factor model ([4]). In order to get a sense of the informational content of each candidate asset pricing factor, we repeat the above procedure for various combinations of input features that correspond with the different factor. Table 2 summarizes the different test runs. The quantities of interest are the alphas (regression intercepts), which are a proxy for the risk-adjusted excess return of the ML portfolio, and the regression R-squared.

Table 2. Test runs

\begin{tabular}{|l|l|l|l|}
\hline Run 1 & Only Market factor (beta) is used. & Run 4 & $\begin{array}{l}\text { Volatility, Conditional Skewness and Liquidity } \\
\text { variables are added. }\end{array}$ \\
\hline Run 2 & Size and Value variables are added. & Run 5 & Macroeconomic variables are added. \\
\hline Run 3 & Momentum variables are added. & Run 6 & Other variables are added. \\
\hline
\end{tabular}

\section{Results}

The test results for all runs and for all models are summarized in Table 3. Detailed results are available at request. Several interesting findings are worth noting. First, we find that the FamaFrench 3-factor model outperforms the CAPM and the Carhart models, implying that the Size and Value factors have significant explanation power over asset price returns in the Romanian 
stock markets, while Momentum does not. This is consistent with the results of [1] obtained using a standard testing approach.

Second, we find that the results significantly change starting in Run 4, when we add factors related to Volatility, Conditional Skewness and Liquidity. This increases the performance of the ML portfolio and generates positive and statistically significant alphas. More precisely, the annualized risk premium (alpha) that is earned by it amounts to $12.6 \%$ measured versus the CAPM and $11.52 \%$ measured versus the Fama-French 3-factor model (using the Carhart 4factor model generates similar results). In the context of the Fama-French 3 -factor model, this result is significant at the $99.55 \%$ level when monthly data is used. This is well above the $t \geq 3$ limit discussed by [9] for making statistical significant discoveries in the large "asset factor zoo". This result leads to the important conclusion that Volatility, Conditional Skewness and Turnover constitute significant risk factors in the emerging stock market of Romania.

Table 3. Results

\begin{tabular}{|c|c|c|c|c|c|c|c|c|c|}
\hline & & Run 1 & & & Run 2 & & & Run 3 & \\
\hline & CAPM & $\mathrm{FF}$ & Carhart & CAPM & $\mathrm{FF}$ & Carhart & CAPM & $\mathrm{FF}$ & Carhart \\
\hline \multirow{2}{*}{ Alpha $(\alpha)$} & -0.0030 & -0.0049 & -0.0045 & 0.0036 & 0.0018 & 0.0024 & -0.0025 & -0.0039 & -0.0034 \\
\hline & $(0.4965)$ & $(0.1564)$ & $(0.1809)$ & $(0.4045)$ & $(0.6131)$ & $(0.4780)$ & $(0.5555)$ & $(0.3055)$ & $(0.3584)$ \\
\hline \multirow[t]{3}{*}{ Adjusted R-squared } & 0.3029 & 0.5895 & 0.5895 & 0.3709 & 0.5771 & 0.5771 & 0.4167 & 0.5268 & 0.5268 \\
\hline & & Run 4 & & & Run 5 & & & Run 6 & \\
\hline & CAPM & $\mathrm{FF}$ & Carhart & CAPM & FF & Carhart & CAPM & $\mathrm{FF}$ & Carhart \\
\hline \multirow[t]{2}{*}{ Alpha $(\alpha)$} & $0.0105 * * *$ & $0.0096^{* * *}$ & $0.0096^{* * *}$ & 0.0092 & 0.0079 & 0.0085 & 0.0089 & 0.0073 & 0.0077 \\
\hline & $(0.0028)$ & $(0.0045)$ & $(0.0046)$ & $(0.1273)$ & $(0.1776)$ & $(0.1396)$ & $(0.1558)$ & $(0.2243)$ & $(0.1991)$ \\
\hline Adjusted R-squared & 0.5472 & 0.6051 & 0.6051 & 0.5967 & 0.6273 & 0.6273 & 0.3491 & 0.3803 & 0.3803 \\
\hline
\end{tabular}

Note. This table reports the alpha $(\alpha)$ and Adjusted $R$-squared of three candidate models that explain ML portfolio returns $\left(R_{p}\right)$, namely:

1) CAPM: $R_{p}-R_{f}=\alpha+\beta_{1}\left(R_{m}-R_{f}\right)+\varepsilon$

2) Fama and French 3-factor: $R_{p}-R_{f}=\alpha+\beta_{1}\left(R_{m}-R_{f}\right)+\beta_{2} S M B+\beta_{3} H M L+\beta_{4} M O M+\varepsilon$

3) Carhart: $R_{p}-R_{f}=\alpha+\beta_{1}\left(R_{m}-R_{f}\right)+\beta_{2} S M B+\beta_{3} H M L+\beta_{4} M O M+\varepsilon$.

$P$-values are reported in round parenthesis. $* * *, * *$ and $*$ denote statistical significance at $1 \%, 5 \%$ and $10 \%$, respectively.

Third, we find that the overall results from Run 4 do not improve in the following Runs when also incorporating other factors. This implies that macroeconomic information is already incorporated in stock prices' data.

\section{Conclusions}

This paper analyzes asset pricing factors in the emerging stock market of Romania using the unconventional approach of Machine Learning (ML) algorithms. On the one hand, we find that Market, Size and Value factors are significant determinants of asset price return, while Momentum is not. On the other hand, we find that Volatility, Conditional Skewness and Turnover are also significant risk factors, together generating average excess returns of roughly $12 \%$ a year, which is significant at $t \geq 3$, well above the threshold discussed by [9] for new discoveries. This is a new an important contribution to the literature, which, among others, shows that ML algorithms can be a very useful practical tool for investors trying to make tactical allocation decisions and capture market risk premiums for their portfolios.

\section{Acknowledgment}

This paper was co-financed from the Human Capital Operational Program 2014-2020, project number POCU / 380/6/13/125245 no. 36482 / 23.05.2019 "Excellence in interdisciplinary PhD 
www.conferenceie.ase.ro

and post- $\mathrm{PhD}$ research, career alternatives through entrepreneurial initiative (EXCIA)", coordinator The Bucharest University of Economic Studies.

\section{References}

[1] A. Anghel, D. Dumitrescu and C. Tudor, "Modeling portfolio returns on Bucharest Stock exchange using the Fama-French multifactor model," Romanian Journal of Economic Forecasting, vol. 17, no. 1, pp.22-46, 2015.

[2] R. Birău, M. Ehsanifar and H. Mohammadi, "Forecasting the Bucharest Stock Exchange BET-C Index based on Artificial Neural Network and Multiple Linear Regressions," in Proc of the 1st WSEAS International Conference on Mathematics, Statistics \& Computer Engineering, Dubrovnik, Croatia, June 2013, pp. 140-145.

[3] I. Breiman, "Random forests," Machine learning, vol. 45, no. 1, pp.5-32, 2001.

[4] M.M. Carhart, "On persistence in mutual fund performance," The Journal of Finance, vol. 52, no. 1, pp.57-82, 1997.

[5] T. Chordia, A. Subrahmanyam and V.R. Anshuman, "Trading activity and expected stock returns," Journal of financial Economics, vol. 59, no. 1, pp.3-32, 2001.

[6] E.F. Fama and K.R. French, "Common risk factors in the returns on stocks and bonds," Journal of Financial Economics, vol. 33, pp.3-56, 1993.

[7] E.F. Fama and K.R. French, "A five-factor asset pricing model," Journal of Financial Economics, vol. 116, no. 1, pp.1-22, 2015.

[8] J. French, "The time traveller's CAPM," Investment Analysts Journal, vol. 46, no. 2, pp.8196, 2017.

[9] C.R. Harvey, Y. Liu and H. Zhu, "... and the cross-section of expected returns," The Review of Financial Studies, vol. 29, no. 1, pp.5-68, 2016.

[10] C.R. Harvey and A. Siddique, "Conditional skewness in asset pricing tests," The Journal of Finance, vol. 55, no. 3, pp.1263-1295, 2000.

[11] M.N. Jan and U. Ayub, "Do the FAMA and FRENCH Five-Factor model forecast well using ANN?," Journal of Business Economics and Management, vol. 20, no. 1, pp.168$191,2019$.

[12] G. Ruxanda and L.M. Badea, "Configuring artificial neural networks for stock market predictions," Technological and Economic Development of Economy, vol. 20, no. 1, pp.116-132, 2014.

[13] W.F. Sharpe, "Capital asset prices: A theory of market equilibrium under conditions of risk," The Journal of Finance, vol. 19, no. 3, pp.425-442, 1964. 